\title{
Direct Synthesis of Quaternary Alkylammonium-Capped Perovskite Nanocrystals for Efficient Blue and Green Light-Emitting Diodes
}

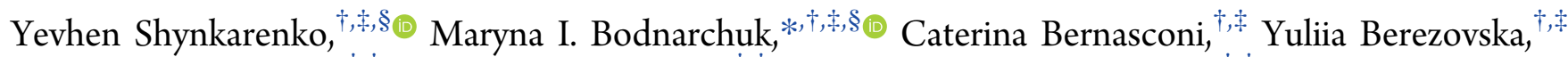
Vladyslav Verteletskyi, ${ }^{\dagger,}$ Stefan T. Ochsenbein, ${ }^{\dagger, \ddagger}$ and Maksym V. Kovalenko ${ }^{*}, \dagger, \ddagger$

${ }^{\dagger}$ Empa - Swiss Federal Laboratories for Materials Science and Technology, Überlandstrasse 129, CH-8600 Dübendorf, Switzerland ${ }^{\ddagger}$ Institute of Inorganic Chemistry, Department of Chemistry and Applied Bioscience, ETH Zürich, Vladimir Prelog Weg 1, CH-8093 Zürich, Switzerland

\section{Supporting Information}

\begin{abstract}
Cesium lead halide nanocrystals $\left(\mathrm{CsPbX}_{3} \mathrm{NCs}\right)$ are new inorganic light sources covering the entire visible spectral range and exhibiting near-unity efficiencies. While the last years have seen rapid progress in green and red electroluminescence from $\mathrm{CsPbX}_{3}$ NCs, the development of blue counterparts remained rather stagnant. Controlling the surface state of $\mathrm{CsPbX}_{3} \mathrm{NCs}$ had proven to be a major factor governing the efficiency of the charge injection and for diminishing the density of traps. Although didodecyldimethylammonium halides (DDAX; $\mathrm{X}=\mathrm{Br}, \mathrm{Cl}$ ) had been known to improve the luminescence of $\mathrm{CsPbX}_{3} \mathrm{NCs}$ when applied postsynthetically, they had not been used as the sole long-chain ammonium ligand directly in the synthesis of these NCs. Herein we report a facile, direct synthesis of DDAX-stabilized $\mathrm{CsPbX}_{3} \mathrm{NCs}$. We then demonstrate blue and green light-emitting diodes, characterized by the electroluminescence at $463-515 \mathrm{~nm}$ and external quantum efficiencies of $9.80 \%$ for green, $4.96 \%$ for sky-blue, and $\mathbf{1 . 0 3 \%}$ for deep-blue spectral regions.
\end{abstract}

$\mathrm{I}$ the past five years, colloidal lead halide perovskite nanocrystals (NCs) of $\mathrm{APbX}_{3}$ composition $(\mathrm{A}=$ cesium, formamidinium, or methylammonium; $\mathrm{X}=\mathrm{Cl}, \mathrm{Br}$, or $\mathrm{I}$ ) have emerged as a novel class of highly fluorescent semiconductor quantum dots with emission spectra spanning the entire visible range, characterized by narrow emission bands $(<100 \mathrm{meV})$ and near-unity photoluminescence quantum yields (PLQY). ${ }^{1-9}$ They are widely researched toward applications in conventional liquid-crystal displays (LCDs) with red and green fluorescent NCs as downconverters in the backlighting; ${ }^{18}$ in the upcoming display technologies such as front-pixel LCD architectures, wherein NCs serve as both light filters and fluorescent emitters; ${ }^{11-15}$ or in LED displays exploiting electroluminescence of perovskite NCs. ${ }^{10,16-19}$ For these display technologies, perovskite NCs offer a compelling suite of attributes: the widest color gamut (due to spectral tunability and narrowband emission) fulfilling the BT.2020 standard, ${ }^{20}$ exceptionally low production costs, as well as satisfactory restriction of hazardous substances compliance. ${ }^{5,21}$ Other applications of luminescent perovskite NCs may include solid-state lighting, ${ }^{22,23}$ solar cell concentrators, ${ }^{24-26}$ and scintillators for X-ray imaging. ${ }^{27,28}$ These NCs are also increasingly recognized as highly potent single-photon emitters for the design of quantum light sources for quantum information technologies. Emission from single-perovskite $\mathrm{NCs}$ is characterized by narrow emission line width, fast radiative decays (10-1000 times faster than in any other colloidal NCs), and long exciton coherence times. ${ }^{29-34}$ In the form of long-range ordered, self-assembled superlattices, these NCs exhibit an accelerated collective mode of emission at cryogenic temperatures, known as superfluerescence, wherein pockets of bundled photons are emitted. ${ }^{35}$

Electroluminescence (EL) of layered 2D lead-halide perovskites had been known since the early 1990s. ${ }^{36}$ The interest in PL from lead halide perovskites had revived in 2013-2014 (e.g., thin-film $\mathrm{MAPbBr}_{3}$ LEDs), ${ }^{37}$ and these efforts had been

Received: September 1, 2019

Accepted: October 11, 2019

Published: October 11, 2019 

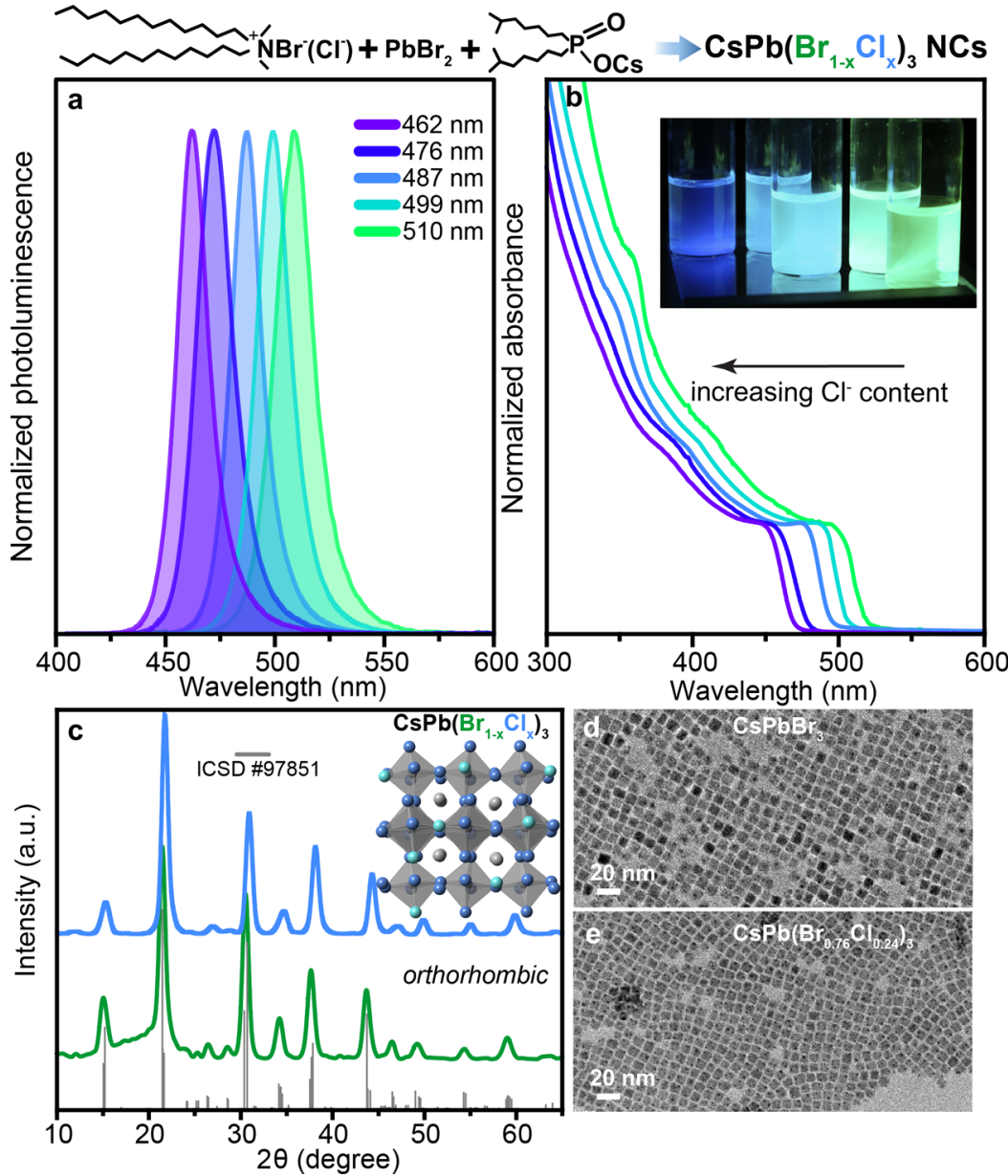

Figure 1. (a and b) Representative PL and absorbance (normalized on excitonic peak) spectra of DDAX-stabilized $\mathrm{CsPb}\left(\mathrm{Br}_{1-x} \mathrm{Cl}_{x}\right)_{3} \mathrm{NCs}$ (inset is the photograph of the colloidal solutions of $\mathrm{CsPb}\left(\mathrm{Br}_{1-x} \mathrm{Cl}_{x}\right)_{3} \mathrm{NCs}$ under UV-light excitation, $\lambda=365 \mathrm{~nm}$ ). (c) X-ray diffraction pattern of $\mathrm{CsPbBr}_{3}$ (green) and $\mathrm{CsPb}\left(\mathrm{Br}_{1-x} \mathrm{Cl}_{x}\right)_{3}$ (blue) and schematic illustration of the orthorhombic lattice of $\left.\mathrm{CsPb}\left(\mathrm{Br}_{1-x} \mathrm{Cl}\right)_{3}\right)_{3} \mathrm{NCs}$. The

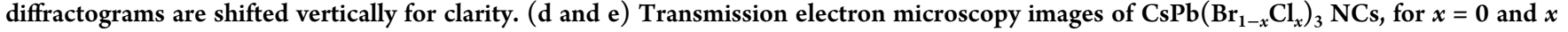
$=0.24$.

motivated by and had paralleled the use of $\mathrm{MAPbX}_{3}$ films in photovoltaics. Soon thereafter, the LED reports extended to the newcomer colloidal $\mathrm{CsPbX}_{3} \mathrm{NCs}^{38}$ as well as their FA and MA NC cousins. ${ }^{39-41}$ Reduction of structural and electronic dimensionalities and efficient electronic passivation of the surfaces and interfaces-either using colloidal NCs as presynthesized inks for the deposition of the emissive layers or by inducing layering, compositional segregation and gradients, and nanograin formations in situ upon coating from precursors-had been sought as major means of enhancing the EL properties. ${ }^{5,42}$ These structures benefit from the reduction of the exciton diffusion length, increasing exciton binding energy, and oscillator strength. ${ }^{19,42,43}$ Rapid progress in the development of perovskite-based LEDs emitting in green ${ }^{18,44-52}$ and $\operatorname{red}^{17,45,53-55}$ led to the demonstration of the external quantum efficiencies (EQE) exceeding 20\%. ${ }^{17,18,56,57}$ As a general trend, NC-based perovskite LEDs fall somewhat behind their precursordeposited thin-film counterparts; for instance, green LEDs based on NCs have thus far yielded lower best EQE value of $16.48 \%$ for $\mathrm{Cs} / \mathrm{FAPbBr}_{3} \mathrm{NCs},{ }^{58}$ while the majority of reports present values well below $10 \%$. Development of blue perovskite LEDs lags far behind those emitting in green and red regions. For the NC-based LEDs the best EQE values are stagnant at ca. $2 \%$ for the region of $460-490 \mathrm{~nm} .^{50,59-62}$ Congreve and co-workers optimized the device architecture for the deep-blue emitting devices by modifying the holetransporting layer surface with Nafion perfluorinated ionomer (PFI) and reached $0.5 \%$ for LEDs emitting at $465 \mathrm{~nm} .{ }^{60}$ More recently, the same group introduced $\mathrm{Mn}^{2+}$ doping for improving PLQY of $\mathrm{CsPb}(\mathrm{Br} / \mathrm{Cl})_{3}$ NCs, thereby boosting the $\mathrm{EQE}$ values to $2.12 \%$ at $466 \mathrm{~nm} .{ }^{60}$ With device brightness of $212 \mathrm{Cd} / \mathrm{m}^{2}$, this is currently the best-performing perovskite LED in the deep blue region. An alternative approach to blue perovskite LEDs is to form an emissive layer from lower dimensionality (i.e., 2D) perovskite materials with bulky cations such as butylammonium (BA), phenylethylammonium (PEA), or phenylbutylammonium (PBA), which separate fewoctahedra-thick lead halide slabs, thereby introducing strong quantum confinement of the excitons and a blue shift of the emission. ${ }^{18,59,63}$ Jun Xing et al. used similar, in situ formed 2D perovskites such as $\mathrm{PEA}_{2} \mathrm{~A}_{1.5} \mathrm{~Pb}_{2.5} \mathrm{Br}_{8.5}$ to fabricate LEDs with EQE of $1.5 \%$ at $490 \mathrm{~nm} .{ }^{64} \mathrm{Mn}^{2+}$ doping of such films $\left(\mathrm{PEA}_{0.2} \mathrm{Cs}_{0.4} \mathrm{MA}_{0.6} \mathrm{~Pb}_{(1-y)} \mathrm{Mn}_{y}(\mathrm{BrCl})_{3}\right)$ slightly improved device efficiency to $0.58 \%$ in the blue. ${ }^{61}$ Such $2 \mathrm{D}$ materials generally exhibit good color stability due to the absence of halide segregation, which is a notable issue with mixed-halide perovskites. $^{62,65}$ State-of-the-art results for such materials 
show that highly confined ( $\mathrm{Cs} / \mathrm{FA}) \mathrm{PbBr}_{3} \mathrm{NCs}$ formed in situ within the quasi-2D PBABr phase allowed achieving EQE of $9.5 \%$ at $483 \mathrm{~nm}$ while showing the brightness of $700 \mathrm{~cd} / \mathrm{m}^{2}{ }^{66}$

The lower performance of green and red NC-based LEDs, compared to the best-performing thin-film counterparts, is commonly attributed to the diverse roles played by long-chain surface capping ligands. On the one hand, the use of long-chain ligands allows for unmatched control over the NC size and shape as well as for ensuring morphological homogeneity within the NC ensemble. These ligands are paramount for the entire life cycle of NCs, from the synthesis of NCs to the retention of the long-term structural and colloidal integrity and for their processing into thin, homogeneous films. On the other hand, controlling and adjusting the inorganic-organic interface of colloidal perovskite NCs had proven to be cumbersome and far more complex as compared to the present state in the surface science of other semiconductor NCs. Structural softness, lattice polarity, and finite solubility in the wide variety of solvents are the factors causing overall lability of perovskite NCs. In this context, highly dynamic and loose binding of the capping ligands, which are thus far most effective in the perovskite NC synthesis [oleic acid (OA) and oleylamine (OLA)], hinders the efficient isolation and purification of NCs and necessitates the presence of the same or alternative ligand in the excess for maintaining the NC stability. This, in turn, imparts the density and other morphological characteristics of the NC films and hence the charge transport through the device. While solution- or solidstate ligand exchange strategies had been highly successful in mitigating these challenges with conventional semiconductor $\mathrm{NCs}$ (typically Cd-, Pb-, and other metal chalcogenides), little progress had been achieved with perovskite NCs. In the context of LED research, the most effective approach has been to use didodecyldimethylammonium bromide (DDAB) for a postsynthetic surface treatment ${ }^{67-72}$ or as an additive during the synthesis. ${ }^{45,73}$ Concomitant passivations of undercoordinated $\mathrm{Pb}$-atoms with bromide anions and strong affinity of the DDA-cation to the surface A-site give rise to both electronic passivation and hence near-unity PLQY values, as well as improved stability and processability, as had been thoroughly examined experimentally and computationally by us ${ }^{74}$ and others. ${ }^{75-77}$ Pan et al. applied DDAB-treatment to $\mathrm{CsPb}(\mathrm{Br} /$ $\mathrm{Cl})_{3} \mathrm{NCs}$ in solutions, reaching $1.9 \% \mathrm{EQE}$ at $490 \mathrm{~nm}$; however, rather low brightness of $35 \mathrm{Cd} / \mathrm{m}^{2}$ was reported. ${ }^{67}$ Combined application of both DDAB and its chloride analog (didodecydimethyammonium chloride, DDAC) had been shown to yield EQE values of $0.86 \%$ at $480 \mathrm{~nm}$ and $0.1 \%$ at $458 \mathrm{~nm}^{72}$

In striving to harness the beneficial effects of DDAX in the most direct manner, we present a novel synthesis of uniform, cuboid $\mathrm{CsPb}\left(\mathrm{Br}_{1-x} \mathrm{Cl}_{x}\right)_{3} \mathrm{NCs}(x=0-0.39)$, wherein $\mathrm{DDAB}$ and/or DDAC are used as a sole ligand system, entirely eliminating the use of OA and OLA. The PL peak position of $\mathrm{Cs} \mathrm{Pb}\left(\mathrm{Br}_{1-x} \mathrm{Cl}_{x}\right)_{3} \mathrm{NCs}$ can be accurately adjusted in the range of $462-510 \mathrm{~nm}$, whereas PLQY reaches $80 \%$. NCs can be wellpurified and consequently allow for fabrication of uniform and compact, thin films. Through judicious optimization of the LED device architecture, high EQE values of 9.8\%, 4.96\%, $3.5 \%, 2.25 \%$, and $1.03 \%$ have been obtained for EL peak positions at 512, 502, 490, 476, and $463 \mathrm{~nm}$, respectively.

Highly luminescent $\mathrm{CsPb}\left(\mathrm{Br}_{1-x} \mathrm{Cl}_{x}\right)_{3} \mathrm{NCs}$ with adjustable chloride content (represented by $x$ as a molar proportion of chloride) were synthesized using hot-injection methodology with DDAX as a sole long-chain $\left(\mathrm{C}_{12}\right)$ capping ligand. The synthesis, outlined in Figure 1, was carried out in mesitylene as a solvent and under nitrogen atmosphere. $\mathrm{PbBr}_{2}$ was first solubilized in mesitylene by mixing with $\mathrm{DDAB}$ or (DDABDDAC) and quickly heated to $150-160{ }^{\circ} \mathrm{C}$ to obtain a transparent colorless solution. $\mathrm{PbBr}_{2}$ alone is not soluble in mesitylene; however, it forms lead-bromide anionic species (presumably $\mathrm{PbBr}_{3}{ }^{-}$and the like) when combined with DDAB at elevated temperatures $\left(>100{ }^{\circ} \mathrm{C}\right)$. Recently, Song et al. reported the use of the quaternary ammonium salts such as tetraoctylammonium bromide (TOAB) in the synthesis of $\mathrm{CsPbBr}_{3} \mathrm{NCs}$ at room temperature, followed by introducing DDAB ligands on the surface of the formed NCs. ${ }^{48}$ While TOAB aids in solubilizing $\mathrm{PbBr}_{2}$ at room temperature, it is too bulky for binding to the NC surface. We find that for the synthesis at elevated temperatures $\mathrm{DDAB}$ alone can play both roles (solubilizer and surfactant). As a source of $\mathrm{Cl}$ ions, DDAC was found to be more convenient than the addition of $\mathrm{PbCl}_{2}$; the latter exhibits very low solubility in nonpolar solvents. A separate $\mathrm{Cs}^{+}$stock solution was prepared by dissolving $\mathrm{Cs}_{2} \mathrm{CO}_{3}$ in diisooctylphosphinic acid and toluene. The Cs solution was then swiftly injected into the first solution. An instant nucleation of NCs is seen as a rapid yellow-green coloration. In this synthesis, we completely omitted OA and OLA as capping ligands, which dynamically and loosely bind to the surface of lead halide perovskite NCs and easily desorb. ${ }^{78}$ Earlier studies indicated that oleate ligands are mostly absent on the surface of such $\mathrm{NCs},{ }^{78,79}$ and the main role of OA is the protonation of OLA. The trouble with OLA cation is that it rapidly loses its proton and desorbs from the NC surface. In contrast, DDA is a quaternary cation with a static positive charge, and hence, no acid is needed in the reaction mixture for adjusting the $\mathrm{pH}$ value. DDAX-stabilized NCs sustain two washing steps by the repetitive destabilization with the moderately polar solvent (acetone-toluene mixture) and redispersion in cyclohexane, as can be judged from the retention of optical characteristics (Figure S1). We note that DDAX-coated NCs are not dispersible in toluene, which is a typical solvent of choice for NCs capped with longer-chain OLA and OA ligands. For the subsequent experimentation with LED devices, we have chosen to focus on weakly confined 9-10 nm large NCs and adjust their band gap energy by the halide composition. A detailed study on the size- and shapecontrol in this DDAX-based synthesis, as well as on the specifics of surface chemistry using NMR spectroscopy and molecular dynamics calculations, is underway and will be published elsewhere.

Elemental analysis of the thin films of purified NCs evidences that the mixing ratios of DDAB:DDAC directly translate into the composition of $\mathrm{CsPb}\left(\mathrm{Br}_{1-x} \mathrm{Cl}_{x}\right)_{3} \mathrm{NCs}$ (Table $\mathrm{S} 1)$. The fact that the halide composition of the NCs reflects an overall halide ratio in the reactions mixture stands in good agreement with OLA/OA-based preparation of $\mathrm{CsPb}$ $\left(\mathrm{Br}_{1-x} \mathrm{Cl}_{x}\right)_{3} \mathrm{NCs}$ (composition adjusted by $\left.\mathrm{PbCl}_{2}: \mathrm{PbBr}_{2}\right)^{1,60,80}$ and other synthesis methodologies, ${ }^{52}$ including postsynthetic compositional adjustments by the anion-exchange reactions. ${ }^{81,82}$ Notably and in contrast, $\mathrm{FAPb}\left(\mathrm{Br}_{1-x} \mathrm{Cl}_{x}\right)_{3}$ NCs are not stable and separate into two monohalide phases, ${ }^{83,84}$ as demonstrated by both the conventional synthesis methodologies ${ }^{84}$ and thorough screening of reaction parameters by the microfluidic-based high-throughput experimentation; ${ }^{85}$ hence, they are not suited for engineering blue LEDs. 
Table 1. Summary of the Material and Device Performance Parameters of LEDs with $\mathrm{CsPb}\left(\mathrm{Br}_{1-x} \mathrm{Cl}_{x}\right)_{3} \mathrm{NCs}_{\text {of }}$ Various $\mathrm{Halide}$ Compositions

\begin{tabular}{|c|c|c|c|c|c|c|c|}
\hline $\begin{array}{c}\text { sample, } \\
\mathrm{CsPb}\left(\mathrm{Br}_{1-x} \mathrm{Cl}_{x}\right)_{3}\end{array}$ & $\begin{array}{l}\text { DDAC/DDAB ratio in the } \\
\text { synthesis }\end{array}$ & $\begin{array}{l}\mathrm{PL} \text { peak }^{a} \\
(\mathrm{~nm})\end{array}$ & $\mathrm{PLQY}^{a}$ & $\begin{array}{l}\text { best } \\
\text { EQE }\end{array}$ & $\begin{array}{c}\mathrm{EQE} \\
@ 100 \mathrm{Cd}\end{array}$ & $\begin{array}{l}\text { best luminance } \\
\qquad\left(\mathrm{Cd} / \mathrm{m}^{2}\right)\end{array}$ & $\begin{array}{l}\text { EL peak position } \\
(\mathrm{nm})\end{array}$ \\
\hline$x=0.39$ & $1: 0$ & 462 & $25 \%$ & $1.03 \%$ & $0.23 \%$ & 193 & 463 \\
\hline$x=0.24$ & $6.5: 3.5$ & 476 & $32 \%$ & $2.25 \%$ & $1.07 \%$ & 678 & 476 \\
\hline$x=0.19$ & $6.1: 3.9$ & 487 & $48 \%$ & $3.5 \%$ & $2.1 \%$ & 2063 & 490 \\
\hline$x=0.11$ & $3.7: 6.3$ & 499 & $62 \%$ & $4.96 \%$ & $3.94 \%$ & 7600 & 502 \\
\hline$x=0$ & $0: 1$ & 510 & $80 \%$ & $9.8 \%$ & $7.3 \%$ & 34700 & 512 \\
\hline
\end{tabular}

${ }^{a}$ In solution.
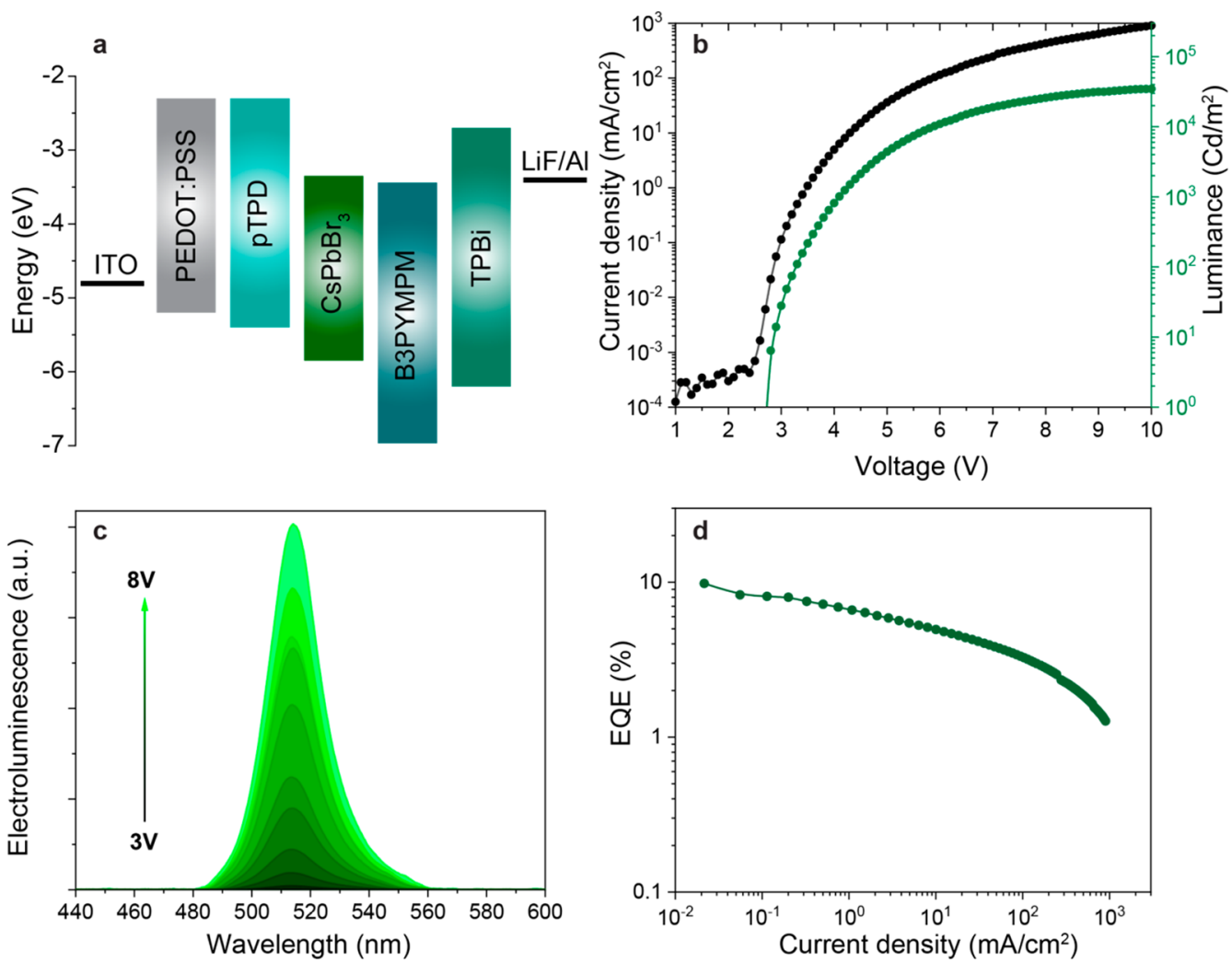

Figure 2. Performance of green-emissive LED with DDAB-capped $\mathrm{CsPbBr}_{3} \mathrm{NCs}$. (a) Energy levels of active layers of the device vs vacuum. (b) Current density and luminance vs applied bias. (c) EL spectra for various driving voltages. (d) External quantum efficiency vs current density through the active area.

The composition-tunable $\mathrm{PL}$ and absorption spectra of purified $\mathrm{CsPb}\left(\mathrm{Br}_{1-x} \mathrm{Cl}_{x}\right)_{3} \mathrm{NCs}(x \leq 0.39$, Figure 1 and Table 1) span the violet to green spectral region $(462-510 \mathrm{~nm})$, with blue shift governed by the quantity of incorporated $\mathrm{Cl}$. Owing to the weak confinement regime at perovskite NC sizes of $8-$ $10 \mathrm{~nm}^{35,86}$ and hence minimal impact of the size-distribution on PL full width at half-maximum (fwhm), a rather narrowband emission had been attained ( $\mathrm{fwhm}=18-20 \mathrm{~nm}$ ).

Purified NCs show PLQYs of 80, 62, 48, 32, 25\% for PL emission bands centered at 510, 499, 487, 476, and $462 \mathrm{~nm}$, respectively (Figure $\mathrm{S} 2$ ). Colloidal solutions of $\mathrm{CsPb}$ $\left(\mathrm{Br}_{1-x} \mathrm{Cl}_{x}\right)_{3}$ NCs obtained by the DDAX approach are stable for months without losing their PLQYs and colloidal stability.

The XRD pattern in Figure 1c confirms the orthorhombic perovskite structure of $\mathrm{CsPb}\left(\mathrm{Br}_{1-x} \mathrm{Cl}_{x}\right)_{3} \mathrm{NCs}$ with no noticeable presence of other phases. All main diffraction peaks in the case of $\mathrm{Br} / \mathrm{Cl}$-containing $\mathrm{NCs}$ were shifted toward larger angles compared to the ICSD-\#97851-pattern (orthorhombic phase of $\mathrm{CsPbr}_{3}$ ), because of the lattice contraction induced by the smaller radius of the $\mathrm{Cl}$ ions, thereby also confirming the formation of the homogeneous solid solution. The TEM image reveals that $\mathrm{CsPbBr}_{3}$ and $\mathrm{CsPb}\left(\mathrm{Br}_{1-x} \mathrm{Cl}_{x}\right)_{3}$ NCs exhibit uniform cuboid morphology with a crystal size of $\sim 9 \mathrm{~nm}$ (Figure 1d,e). The colloids and corresponding dropcasted films from $\mathrm{CsPb}\left(\mathrm{Br}_{1-x} \mathrm{Cl}_{x}\right)_{3} \mathrm{NCs}$ were also characterized by the TRPL. All samples showed biexponential decay lifetimes in solution with intensity averaged lifetime values of $10.5,4.6,10.4,7.7$, and 20.7 ns (for $x$-values from 0.39 to 0 ), from bluest to greenest samples respectively (Figure S3). Drop-cast films generally exhibited shorter lifetimes of 8.5 , $1.95,2.8,2.84$, and 2.34 ns for the same samples, correspondingly.

Initial electroluminescence tests had been conducted on $\mathrm{Cl}$ free samples $\left(\mathrm{CsPbBr}_{3} \mathrm{NCs}\right)$ in order to benchmark the utility of the new synthesis and compare to the extensive prior art on $\mathrm{CsPbBr}_{3}$ NC LEDs. The best LED characteristics were attained when using $15 \mathrm{~nm}$ layers of B3PYMPM $(4,6-$ bis(3,5-di(pyridin-3-yl)phenyl)-2-methylpyrimidine) or 3TPYMB (3,3',3" - [borylidynetris (2,4,6-trimethyl-3,1phenylene)] tris[pyridine]) as hole-blocking layers (HBLs), in 

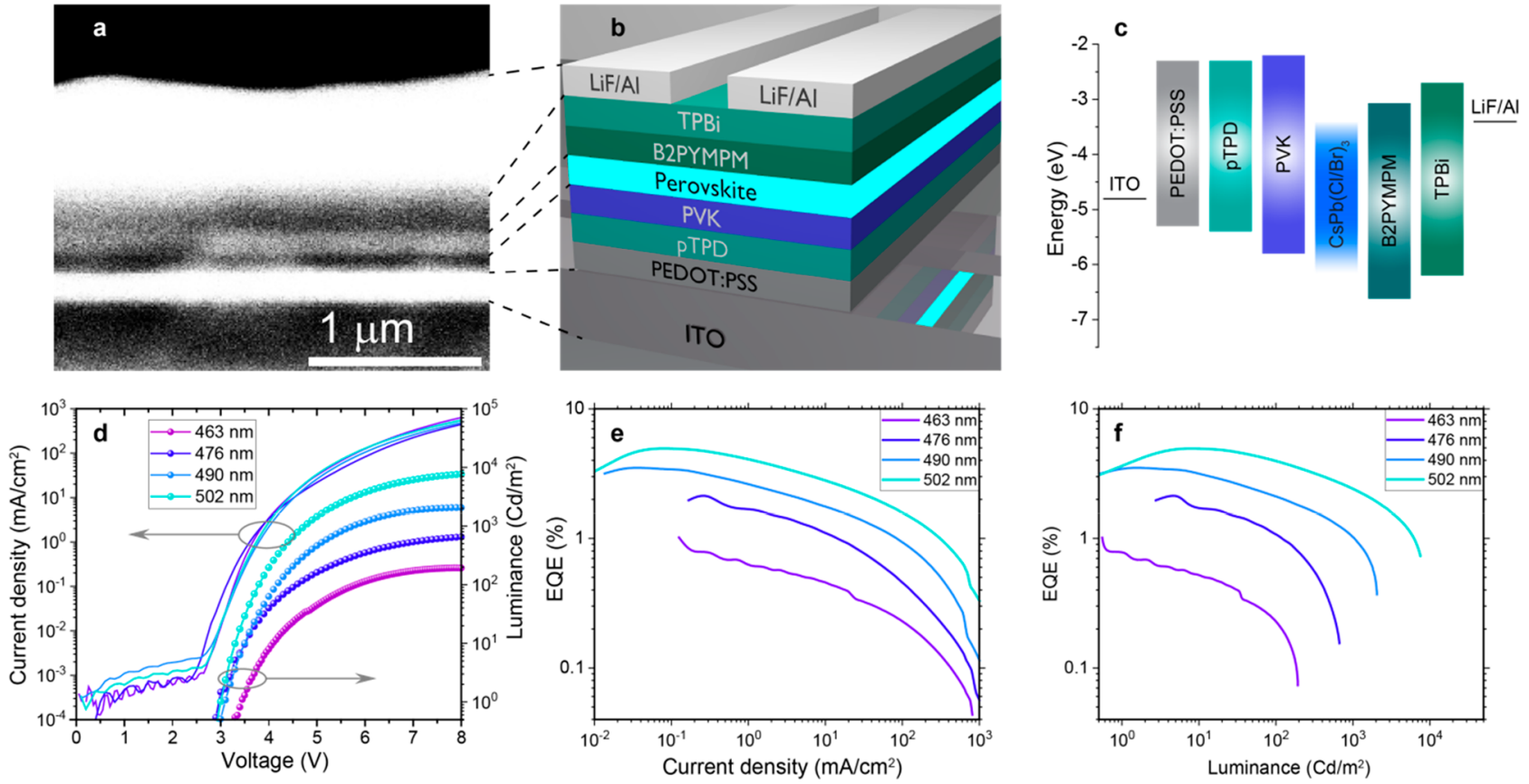

Figure 3. ( $a$ and b) SEM cross-sectional image and corresponding schematic of the blue LED stack. (c) Work function of electrodes and band gap values of the different materials used in the LED stack, energies vs vacuum. (d) Current density and luminance of the devices with various EL peak positions as a function of voltage. (e and $f$ ) EQE of the devices with various EL peak positions as a function of current density and luminance.
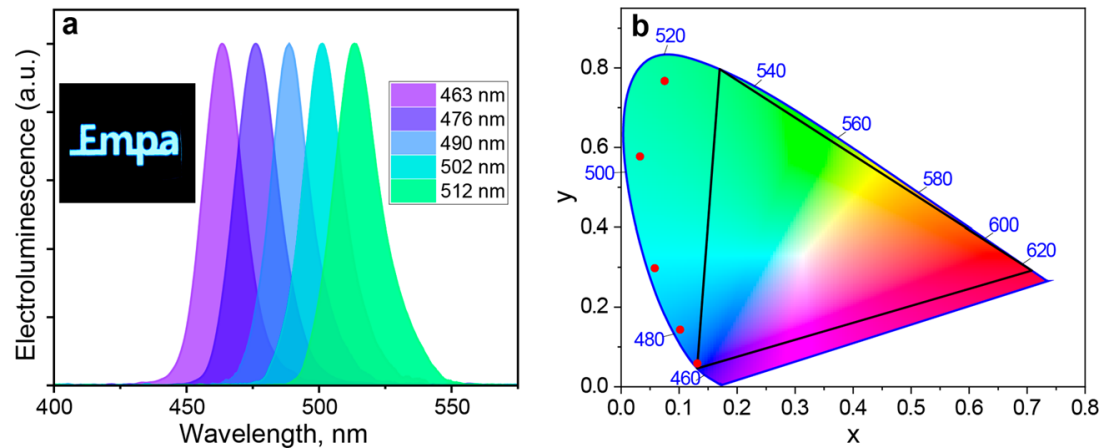

Figure 4. (a) EL spectra of the LEDs. Legend reveals corresponding EL peak position. Inset shows photo of the EL of the operating device with Empa logo. (b) Commission Internationale de l'Eclairage CIE 1931 color diagram. Black triangle represents BT.2020 (Rec2020) color coordinates. Red dots mark coordinates of LEDs presented in this work.

combination with a $45 \mathrm{~nm}$ layer of TPBi (1,3,5-tris(1-phenyl$1 \mathrm{H}$-benzimidazol-2-yl)benzene) as an electron transporting layer (ETL) and pTPD (poly[N, $\mathrm{N}^{\prime}$-bis(4-butylphenyl)-N, $\mathrm{N}^{\prime}$ bisphenylbenzidine]) as a hole-transporting layer (HTL). Figure S4 evidences the beneficial effects of HBLs by comparison with HBL-free devices. The best-efficiency devices were those employing a $15 \mathrm{~nm}$ layer of B3PYMPM as an HBL and a $45 \mathrm{~nm}$ layer of TPBi as an ETL. These devices presumably benefit from hole localization in the emissive layer and from the additional barrier for the electron injection (at $\mathrm{TPBi}$ ), thereby balancing the barrier existing for the injection of holes. This device architecture, together with the judicious optimization of the NC purification (the choice of solvents and nonsolvents and their amounts, as well as number of purification steps etc.), yielded a champion green device, with characteristics shown in Figure 2. Specifically, the EL peak centered at $515 \mathrm{~nm}$ was characterized by EQE values of up to 9.8\%. High EQE values are satisfactorily retained at higher current densities, allowing for obtaining brightness of 34700
$\mathrm{Cd} / \mathrm{m}^{2}$. Other reports on LEDs employing $\mathrm{CsPbBr}_{3} \mathrm{NCs}$ with $\mathrm{DDAB}$ treatment have presented EQE values of $7-9.7 \%$ and brightness of $2269-15000 \mathrm{Cd} / \mathrm{m}^{2}{ }^{70,87}$

Blue-emitting LEDs were fabricated with the device structure proposed by Gangishetty et al., where a TFB (poly[(9,9-dioctylfluorenyl-2,7-diyl)-co-(4,4' -(N-(4-s-butylphenyl) diphenylamine)]) layer covered with Nafion perfluorinated ionomer (PFI) is used as an HTL for improved hole injection. ${ }^{60}$ Figure S5 shows device performance of our LEDs based on DDAX-stabilized $\mathrm{CsPb}\left(\mathrm{Br}_{1-x} \mathrm{Cl}_{x}\right)_{3} \mathrm{NCs}$ with EL peak at $480 \mathrm{~nm}$. While EQE of $\sim 0.57 \%$ is a modest improvement in comparison to ref $60(0.44 \%$ at $481 \mathrm{~nm}$, OLA/OA-synthesized NCs), the brightness was approximately 10 -fold higher and reached $2500 \mathrm{Cd} / \mathrm{m}^{2}$ (vs $212 \mathrm{Cd} / \mathrm{m}^{2}$ in ref $60)$. We should also note that we were not able to fully suppress the EL from the TFB layer (at $\sim 430 \mathrm{~nm}$ ) by the application of PFI, presumably because of the suboptimal thickness of the perovskite NC layer and hence electron injection into TFB. 
Additional device structure optimization was made by using a two-step hole injection with both PTPD and another HTL material with a deeper highest occupied molecular orbital level, namely, PVK (poly[9-vinylcarbazole]). The best device structure for the blue LEDs was the following (Figure 3ac): ITO/PEDOT:PSS/pTPD/PVK/NCs/B2PYMPM (15 $\mathrm{nm}) / \mathrm{TPBi}(45 \mathrm{~nm}) / \mathrm{LiF}(1.2 \mathrm{~nm}) / \mathrm{Al}(100 \mathrm{~nm})$. Currentdensity curves reveal low leakage currents of the presented device structure (Figure 3d). The turn-on voltages are in the range of $3-3.4 \mathrm{~V}$, which is still higher than the emissive material band gaps $(2.47-2.68 \mathrm{eV})$. EQE versus currentdensity and luminance curves of the devices presented in Figure $3 \mathrm{e}, \mathrm{f}$ show efficiency drops at higher currents/luminance. The best EQE values are $4.96 \%, 3.5 \%, 2.25 \%$, and $1.03 \%$ for the devices with a EL peak at 502, 490, 476, and $463 \mathrm{~nm}$, respectively (Figure S6). Lower efficiency in a deep-blue spectral region might be associated with the lower PLQYs of Cl-containing NC perovskites.

All devices showed high color purity and narrow EL spectra without any visible emission from the transport layers (Figure $4 \mathrm{a}$ ), indicating that the layer of NCs is the preferable recombination zone in the devices. Chromaticity coordinates achieved in the devices presented here are presented on Figure $4 \mathrm{~b}$ and Table S2, with one of the devices reaching the recommended blue color for BT.2020. ${ }^{62}$ Table 1 summarizes the synthesis conditions and optical and optoelectronic properties of $\mathrm{CsPb}\left(\mathrm{Br}_{1-x} \mathrm{Cl}_{x}\right)_{3} \mathrm{NCs}$ and respective LEDs.

We further tested the device stability and evolution of the electroluminescence. Increased driving voltage does not cause changes in the EL peak position (Figure S7). The constantcurrent driving under initial brightness of $100 \mathrm{Cd} / \mathrm{m}^{2}$ of the device with $\mathrm{CsPb}\left(\mathrm{Br}_{0.76} \mathrm{Cl}_{0.24}\right)_{3}$ NCs results in the EL intensity drop to $20 \%$ of the initial value within 26 s, which, although fast, is comparable to the best blue-emitting perovskite LEDs made from both the NCs and quasi-2D perovskites. ${ }^{61,64,66} \mathrm{We}$ also observe red shift of the electroluminescence spectrum (Figure S8). Such color instability is commonplace in perovskite devices and is caused by halide ion migration during the device operation. ${ }^{88-91}$ In $\mathrm{Br} / \mathrm{I}$ systems, the halide segregation is readily observed under illumination and without applied electric bias and is commonly assumed to occur under the action of the local electric field induced by free and trapped charge carriers. ${ }^{92,93}$ In the case of electrical charge injection, this effect might be more pronounced because of possible charge imbalance and higher electrical field. While reported EQEs of perovskite LEDs are rapidly increasing, the stability of devices remains a major obstacle. Further studies are required to unveil the factors governing the long-term stability, which may include degradation of the charge-transporting layers or the perovskite layer. We tend to assume that the fundamental issue lies with the facile electrochemical reduction of $\mathrm{Pb}^{2+}$ to metallic $\mathrm{Pb}$. If true, this degradation path should be more pronounced for higher electronegativities of halide, e.g. for chlorides.

In summary, we reported a direct synthesis of long-chain quaternary ammonium-capped $\mathrm{Cs} \mathrm{Pb}\left(\mathrm{Br}_{1-x} \mathrm{Cl}_{x}\right)_{3} \mathrm{NCs}$, namely employing DDAX as the sole ligand in the hot-injection synthesis. With its $\mathrm{C}_{12}$-hydrocarbon chains, this ligand is considerably shorter than OLA and OA $\left(\mathrm{C}_{18}\right)$, favoring the application of such NCs in LEDs. Green-emissive LEDs exhibit a peak EQE of $9.8 \%$ and brightness of $34700 \mathrm{Cd} / \mathrm{m}^{2}$ and are, to the best of our knowledge, the most efficient devices based on $\mathrm{CsPbBr}_{3}$ NCs. Application of double hole-transporting layers and additional hole-blocking layers afforded efficient blue LEDs (EQE $=1-5 \%$ at EL peaks of $460-500 \mathrm{~nm}$ ). Future work should focus on the maximization of PLQY values of the NCs before integration into the LEDs. Another highly promising venue is solid-state chemical treatment, e.g. by dipping the films of DDAX-capped NCs into solutions of diverse chemical species, which could allow for passivation of the trap states.

\section{ASSOCIATED CONTENT}

\section{S Supporting Information}

The Supporting Information is available free of charge on the ACS Publications website at DOI: 10.1021/acsenergylett.9b01915.

Experimental methods; materials; green LED device structure optimization; spectra of the blue-emissive LEDs with various driving voltages; device stability test; color coordinates of the LEDs (PDF)

\section{AUTHOR INFORMATION}

\section{Corresponding Authors}

*E-mail: mvkovalenko@ethz.ch

*E-mail: maryna.bodnarchuk@empa.ch

ORCID $\odot$

Yevhen Shynkarenko: 0000-0002-1587-1752

Maryna I. Bodnarchuk: 0000-0001-6597-3266

Maksym V. Kovalenko: 0000-0002-6396-8938

\section{Author Contributions}

${ }^{\S}$ Y.S. and M.I.B. contributed equally.

\section{Notes}

The authors declare no competing financial interest.

\section{ACKNOWLEDGMENTS}

Authors are thankful to Dr. Mario Ochoa Gomes and Dr. Yaroslav Romanyuk for access to the TRPL measurement setup, Dr. Oleksii Liashenko for help with SEM imaging, and Dr. Frank Krumeich for SEM-EDS compositional analysis. The authors are grateful to the Scientific Center for Optical and Electron Microscopy (ScopeM, ETHZ) and Empa Electron Microscopy Center for use of their instruments. This project has received funding from the European Research Council (ERC) under the European Union's Horizon 2020 research and innovation program (Grant Agreement No. [819740], project SCALE-HALO), from Swiss Federal Laboratories for Materials Science and Technology (Empa), and Swiss Federal Institute of Technology in Zurich (ETH Zurich).

\section{REFERENCES}

(1) Protesescu, L.; Yakunin, S.; Bodnarchuk, M. I.; Krieg, F.; Caputo, R.; Hendon, C. H.; Yang, R. X.; Walsh, A.; Kovalenko, M. V. Nanocrystals of Cesium Lead Halide Perovskites $\left(\mathrm{CsPbX}_{3}, \mathrm{X}=\mathrm{Cl}, \mathrm{Br}\right.$, and I): Novel Optoelectronic Materials Showing Bright Emission with Wide Color Gamut. Nano Lett. 2015, 15 (6), 3692-3696.

(2) Schmidt, L. C.; Pertegas, A.; Gonzalez-Carrero, S.; Malinkiewicz, O.; Agouram, S.; Minguez Espallargas, G.; Bolink, H. J.; Galian, R. E.; Perez-Prieto, J. Nontemplate Synthesis of $\mathrm{CH}_{3} \mathrm{NH}_{3} \mathrm{PbBr}_{3}$ Perovskite Nanoparticles. J. Am. Chem. Soc. 2014, 136 (3), 850-853.

(3) Protesescu, L.; Yakunin, S.; Bodnarchuk, M. I.; Bertolotti, F.; Masciocchi, N.; Guagliardi, A.; Kovalenko, M. V. Monodisperse Formamidinium Lead Bromide Nanocrystals with Bright and Stable Green Photoluminescence. J. Am. Chem. Soc. 2016, 138 (43), 1420214205. 
(4) Pradhan, N. Tips and Twists in Making High Photoluminescence Quantum Yield Perovskite Nanocrystals. ACS Energy Lett 2019, 4 (7), 1634-1638.

(5) Akkerman, Q. A.; Raino, G.; Kovalenko, M. V.; Manna, L. Genesis, Challenges and Opportunities For Colloidal Lead Halide Perovskite Nanocrystals. Nat. Mater. 2018, 17 (5), 394-405.

(6) Swarnkar, A.; Mir, W. J.; Chakraborty, R.; Jagadeeswararao, M.; Sheikh, T.; Nag, A. Are Chalcogenide Perovskites an Emerging Class of Semiconductors for Optoelectronic Properties and Solar Cell? Chem. Mater. 2019, 31 (3), 565-575.

(7) Shamsi, J.; Urban, A. S.; Imran, M.; De Trizio, L.; Manna, L. Metal Halide Perovskite Nanocrystals: Synthesis, Post-Synthesis Modifications, and Their Optical Properties. Chem. Rev. 2019, 119 (5), 3296-3348.

(8) Huang, H.; Bodnarchuk, M. I.; Kershaw, S. V.; Kovalenko, M. V.; Rogach, A. L. Lead Halide Perovskite Nanocrystals in the Research Spotlight: Stability and Defect Tolerance. ACS Energy Lett 2017, 2 (9), 2071-2083.

(9) Li, Y.; Zhang, X.; Huang, H.; Kershaw, S. V.; Rogach, A. L. Advances in Metal Halide Perovskite Nanocrystals: Synthetic Strategies, Growth Mechanisms, and Optoelectronic Applications. Mater. Today 2019, 5. DOI: 10.1016/j.mattod.2019.06.007.

(10) Lu, M.; Zhang, Y.; Wang, S.; Guo, J.; Yu, W. W.; Rogach, A. L. Metal Halide Perovskite Light-Emitting Devices: Promising Technology for Next-Generation Displays. Adv. Funct. Mater. 2019, 29 (30), 1902008.

(11) He, Z.; Zhang, C.; Dong, Y.; Wu, S.-T. Emerging Perovskite Nanocrystals-Enhanced Solid-State Lighting and Liquid-Crystal Displays. Crystals 2019, 9 (2), 59.

(12) Yoon, H. C.; Lee, H.; Kang, H.; Oh, J. H.; Do, Y. R. Highly Efficient Wide-Color-Gamut QD-emissive LCDs using Red and Green Perovskite Core/Shell QDs. J. Mater. Chem. C 2018, 6 (47), 13023-13033.

(13) Ko, Y. H.; Jalalah, M.; Lee, S. J.; Park, J. G. Super Ultra-High Resolution Liquid-Crystal-Display Using Perovskite Quantum-Dot Functional Color-Filters. Sci. Rep. 2018, 8 (1), 12881.

(14) Wei, Y.; Cheng, Z.; Lin, J. An Overview on Enhancing the Stability of Lead Halide Perovskite Quantum Dots and their Applications in Phosphor-Converted LEDs. Chem. Soc. Rev. 2019, 48 (1), 310-350.

(15) Chen, N.; Bai, Z.; Wang, Z.; Ji, H.; Liu, R.; Cao, C.; Wang, H.; Jiang, F.; Zhong, H. P-119: Low Cost Perovskite Quantum Dots Film Based Wide Color Gamut Backlight Unit for LCD TVs. Dig. Tech. Pap. - Soc. Inf. Disp. Int. Symp. 2018, 49 (1), 1657-1659.

(16) Li, C. H. A.; Zhou, Z.; Vashishtha, P.; Halpert, J. E. The Future Is Blue (LEDs): Why Chemistry Is the Key to Perovskite Displays. Chem. Mater. 2019, 31 (16), 6003-6032.

(17) Chiba, T.; Hayashi, Y.; Ebe, H.; Hoshi, K.; Sato, J.; Sato, S.; Pu, Y.-J.; Ohisa, S.; Kido, J. Anion-Exchange Red Perovskite Quantum Dots with Ammonium Iodine Salts for Highly Efficient Light-Emitting Devices. Nat. Photonics 2018, 12 (11), 681-687.

(18) Lin, K.; Xing, J.; Quan, L. N.; de Arquer, F. P. G.; Gong, X.; Lu, J.; Xie, L.; Zhao, W.; Zhang, D.; Yan, C.; Li, W.; Liu, X.; Lu, Y.; Kirman, J.; Sargent, E. H.; Xiong, Q.; Wei, Z. Perovskite LightEmitting Diodes with External Quantum Efficiency Exceeding 20\%. Nature 2018, 562 (7726), 245-248.

(19) Quan, L. N.; Rand, B. P.; Friend, R. H.; Mhaisalkar, S. G.; Lee, T. W.; Sargent, E. H. Perovskites for Next-Generation Optical Sources. Chem. Rev. 2019, 119 (12), 7444-7477.

(20) Recommendation ITU-R BT.2020-2. Parameter Values for Ultra-High Definition Television Systems for Production and International Programme Exchange. https://www.itu.int/rec/R-REC-BT. 2020/en (accessed Aug. 10, 2019).

(21) Babayigit, A.; Boyen, H.-G.; Conings, B. Environment Versus Sustainable Energy: The Case of Lead Halide Perovskite-based Solar Cells. MRS Energy \& Sustainability 2018, 5, E1.

(22) Adjokatse, S.; Fang, H.-H.; Loi, M. A. Broadly Tunable Metal Halide Perovskites for Solid-State Light-Emission Applications. Mater. Today 2017, 20 (8), 413-424.
(23) Chen, D.; Fang, G.; Chen, X. Silica-Coated Mn-Doped $\mathrm{CsPb}(\mathrm{Cl} / \mathrm{Br})_{3}$ Inorganic Perovskite Quantum Dots: Exciton-to-Mn Energy Transfer and Blue-Excitable Solid-State Lighting. ACS Appl. Mater. Interfaces 2017, 9 (46), 40477-40487.

(24) Luo, X.; Ding, T.; Liu, X.; Liu, Y.; Wu, K. Quantum-Cutting Luminescent Solar Concentrators Using Ytterbium-Doped Perovskite Nanocrystals. Nano Lett. 2019, 19 (1), 338-341.

(25) Meinardi, F.; Akkerman, Q. A.; Bruni, F.; Park, S.; Mauri, M.; Dang, Z.; Manna, L.; Brovelli, S. Doped Halide Perovskite Nanocrystals for Reabsorption-Free Luminescent Solar Concentrators. ACS Energy Lett 2017, 2 (10), 2368-2377.

(26) Zhao, H.; Zhou, Y.; Benetti, D.; Ma, D.; Rosei, F. Perovskite Quantum Dots Integrated in Large-Area Luminescent Solar Concentrators. Nano Energy 2017, 37, 214-223.

(27) Chen, Q.; Wu, J.; Ou, X.; Huang, B.; Almutlaq, J.; Zhumekenov, A. A.; Guan, X.; Han, S.; Liang, L.; Yi, Z.; Li, J.; Xie, X.; Wang, Y.; Li, Y.; Fan, D.; Teh, D. B. L.; All, A. H.; Mohammed, O. F.; Bakr, O. M.; Wu, T.; Bettinelli, M.; Yang, H.; Huang, W.; Liu, X. All-Inorganic Perovskite Nanocrystal Scintillators. Nature 2018, 561 (7721), 88-93.

(28) Heo, J. H.; Shin, D. H.; Park, J. K.; Kim, D. H.; Lee, S. J.; Im, S. H. High-Performance Next-Generation Perovskite Nanocrystal Scintillator for Nondestructive X-Ray Imaging. Adv. Mater. 2018, 30, 1801743 .

(29) Makarov, N. S.; Guo, S.; Isaienko, O.; Liu, W.; Robel, I.; Klimov, V. I. Spectral and Dynamical Properties of Single Excitons, Biexcitons, and Trions in Cesium-Lead-Halide Perovskite Quantum Dots. Nano Lett. 2016, 16 (4), 2349-2362.

(30) Utzat, H.; Sun, W.; Kaplan, A. E. K.; Krieg, F.; Ginterseder, M.; Spokoyny, B.; Klein, N. D.; Shulenberger, K. E.; Perkinson, C. F.; Kovalenko, M. V.; Bawendi, M. G. Coherent Single-Photon Emission from Colloidal Lead Halide Perovskite Quantum Dots. Science 2019, 363 (6431), 1068-1072.

(31) Tamarat, P.; Bodnarchuk, M. I.; Trebbia, J. B.; Erni, R.; Kovalenko, M. V.; Even, J.; Lounis, B. The Ground Exciton State of Formamidinium Lead Bromide Perovskite Nanocrystals is a Singlet Dark State. Nat. Mater. 2019, 18 (7), 717-724.

(32) Belykh, V. V.; Yakovlev, D. R.; Glazov, M. M.; Grigoryev, P. S.; Hussain, M.; Rautert, J.; Dirin, D. N.; Kovalenko, M. V.; Bayer, M. Coherent Spin Dynamics of Electrons and Holes in $\mathrm{CsPbBr}_{3}$ Perovskite Crystals. Nat. Commun. 2019, 10 (1), 673.

(33) Becker, M. A.; Vaxenburg, R.; Nedelcu, G.; Sercel, P. C.; Shabaev, A.; Mehl, M. J.; Michopoulos, J. G.; Lambrakos, S. G.; Bernstein, N.; Lyons, J. L.; Stoferle, T.; Mahrt, R. F.; Kovalenko, M. V.; Norris, D. J.; Raino, G.; Efros, A. L. Bright Triplet Excitons in Caesium Lead Halide Perovskites. Nature 2018, 553 (7687), 189193.

(34) Becker, M. A.; Scarpelli, L.; Nedelcu, G.; Raino, G.; Masia, F.; Borri, P.; Stoferle, T.; Kovalenko, M. V.; Langbein, W.; Mahrt, R. F. Long Exciton Dephasing Time and Coherent Phonon Coupling in CsPbBr ${ }_{2} \mathrm{Cl}$ Perovskite Nanocrystals. Nano Lett. 2018, 18 (12), 75467551.

(35) Raino, G.; Becker, M. A.; Bodnarchuk, M. I.; Mahrt, R. F.; Kovalenko, M. V.; Stoferle, T. Superfluorescence From Lead Halide Perovskite Quantum Dot Superlattices. Nature 2018, 563 (7733), 671-675.

(36) Era, M.; Morimoto, S.; Tsutsui, T.; Saito, S. Organic-Inorganic Heterostructure Electroluminescent Device using a Layered Perovskite Semiconductor $\left(\mathrm{C}_{6} \mathrm{H}_{5} \mathrm{C}_{2} \mathrm{H}_{4} \mathrm{NH}_{3}\right)_{2} \mathrm{PbI}_{4}$. Appl. Phys. Lett. 1994, 65 (6), 676-678.

(37) Tan, Z.-K.; Moghaddam, R. S.; Lai, M. L.; Docampo, P.; Higler, R.; Deschler, F.; Price, M.; Sadhanala, A.; Pazos, L. M.; Credgington, D.; Hanusch, F.; Bein, T.; Snaith, H. J.; Friend, R. H. Bright LightEmitting Diodes Based on Organometal Halide Perovskite. Nat. Nanotechnol. 2014, 9, 687.

(38) Song, J.; Li, J.; Li, X.; Xu, L.; Dong, Y.; Zeng, H. Quantum Dot Light-Emitting Diodes Based on Inorganic Perovskite Cesium Lead Halides $\left(\mathrm{CsPbX}_{3}\right)$. Adv. Mater. 2015, 27 (44), 7162-7167. 
(39) Ling, Y.; Yuan, Z.; Tian, Y.; Wang, X.; Wang, J. C.; Xin, Y.; Hanson, K.; Ma, B.; Gao, H. Bright Light-Emitting Diodes Based on Organometal Halide Perovskite Nanoplatelets. Adv. Mater. 2016, 28 (2), 305-311.

(40) Huang, H.; Zhao, F.; Liu, L.; Zhang, F.; Wu, X. G.; Shi, L.; Zou, B.; Pei, Q.; Zhong, H. Emulsion Synthesis of Size-Tunable $\mathrm{CH}_{3} \mathrm{NH}_{3} \mathrm{PbBr}_{3}$ Quantum Dots: An Alternative Route toward Efficient Light-Emitting Diodes. ACS Appl. Mater. Interfaces 2015, 7 (51), 28128-28133.

(41) Perumal, A.; Shendre, S.; Li, M.; Tay, Y. K.; Sharma, V. K.; Chen, S.; Wei, Z.; Liu, Q.; Gao, Y.; Buenconsejo, P. J.; Tan, S. T.; Gan, C. L.; Xiong, Q.; Sum, T. C.; Demir, H. V. High Brightness Formamidinium Lead Bromide Perovskite Nanocrystal Light Emitting Devices. Sci. Rep. 2016, 6, 36733.

(42) Cho, H.; Jeong, S. H.; Park, M. H.; Kim, Y. H.; Wolf, C.; Lee, C. L.; Heo, J. H.; Sadhanala, A.; Myoung, N.; Yoo, S.; Im, S. H.; Friend, R. H.; Lee, T. W. Overcoming the Electroluminescence Efficiency Limitations of Perovskite Light-Emitting Diodes. Science 2015, 350 (6265), 1222-1225.

(43) Droseros, N.; Longo, G.; Brauer, J. C.; Sessolo, M.; Bolink, H. J.; Banerji, N. Origin of the Enhanced Photoluminescence Quantum Yield in $\mathrm{MAPbBr}_{3}$ Perovskite with Reduced Crystal Size. ACS Energy Lett 2018, 3 (6), 1458-1466.

(44) Yan, F.; Xing, J.; Xing, G.; Quan, L.; Tan, S. T.; Zhao, J.; Su, R.; Zhang, L.; Chen, S.; Zhao, Y.; Huan, A.; Sargent, E. H.; Xiong, Q.; Demir, H. V. Highly Efficient Visible Colloidal Lead-Halide Perovskite Nanocrystal Light-Emitting Diodes. Nano Lett. 2018, 18 (5), 3157-3164.

(45) Han, D.; Imran, M.; Zhang, M.; Chang, S.; Wu, X.-g.; Zhang, X.; Tang, J.; Wang, M.; Ali, S.; Li, X.; Yu, G.; Han, J.; Wang, L.; Zou, B.; Zhong, H. Efficient Light-Emitting Diodes Based on in Situ Fabricated $\mathrm{FAPbBr}_{3}$ Nanocrystals: The Enhancing Role of the Ligand-Assisted Reprecipitation Process. ACS Nano 2018, 12 (8), $8808-8816$.

(46) Shi, Y.; Xi, J.; Lei, T.; Yuan, F.; Dai, J.; Ran, C.; Dong, H.; Jiao, B.; Hou, X.; Wu, Z. Rubidium Doping for Enhanced Performance of Highly Efficient Formamidinium-Based Perovskite Light-Emitting Diodes. ACS Appl. Mater. Interfaces 2018, 10 (11), 9849-9857.

(47) Lee, S.; Park, J. H.; Nam, Y. S.; Lee, B. R.; Zhao, B.; Di Nuzzo, D.; Jung, E. D.; Jeon, H.; Kim, J.-Y.; Jeong, H. Y.; Friend, R. H.; Song, M. H. Growth of Nanosized Single Crystals for Efficient Perovskite Light-Emitting Diodes. ACS Nano 2018, 12 (4), 3417-3423.

(48) Song, J.; Li, J.; Xu, L.; Li, J.; Zhang, F.; Han, B.; Shan, Q.; Zeng, H. Room-Temperature Triple-Ligand Surface Engineering Synergistically Boosts Ink Stability, Recombination Dynamics, and Charge Injection toward EQE-11.6\% Perovskite QLEDs. Adv. Mater. 2018, 30 (30), 1800764.

(49) Tong, Y.; Yao, E.-P.; Manzi, A.; Bladt, E.; Wang, K.; Döblinger, M.; Bals, S.; Müller-Buschbaum, P.; Urban, A. S.; Polavarapu, L.; Feldmann, J. Spontaneous Self-Assembly of Perovskite Nanocrystals into Electronically Coupled Supercrystals: Toward Filling the Green Gap. Adv. Mater. 2018, 30 (29), 1801117.

(50) Ban, M.; Zou, Y.; Rivett, J. P. H.; Yang, Y.; Thomas, T. H.; Tan, Y.; Song, T.; Gao, X.; Credgington, D.; Deschler, F.; Sirringhaus, H.; Sun, B. Solution-Processed Perovskite Light Emitting Diodes with Efficiency Exceeding 15\% through Additive-Controlled Nanostructure Tailoring. Nat. Commun. 2018, 9 (1), 3892.

(51) Sun, H.; Yang, Z.; Wei, M.; Sun, W.; Li, X.; Ye, S.; Zhao, Y.; Tan, H.; Kynaston, E. L.; Schon, T. B.; Yan, H.; Lu, Z.-H.; Ozin, G. A.; Sargent, E. H.; Seferos, D. S. Chemically Addressable Perovskite Nanocrystals for Light-Emitting Applications. Adv. Mater. 2017, 29 (34), 1701153.

(52) Krieg, F.; Ochsenbein, S. T.; Yakunin, S.; Ten Brinck, S.; Aellen, P.; Süess, A.; Clerc, B.; Guggisberg, D.; Nazarenko, O.; Shynkarenko, Y.; Kumar, S.; Shih, C. J.; Infante, I.; Kovalenko, M. V. Colloidal $\mathrm{CsPbX}_{3}(\mathrm{X}=\mathrm{Cl}, \mathrm{Br}, \mathrm{I})$ Nanocrystals 2.0: Zwitterionic Capping Ligands for Improved Durability and Stability. ACS Energy Lett 2018, 3 (3), 641-646.
(53) Lignos, I.; Morad, V.; Shynkarenko, Y.; Bernasconi, C.; Maceiczyk, R. M.; Protesescu, L.; Bertolotti, F.; Kumar, S.; Ochsenbein, S. T.; Masciocchi, N.; Guagliardi, A.; Shih, C.-J.; Bodnarchuk, M. I.; deMello, A. J.; Kovalenko, M. V. Exploration of Near-Infrared-Emissive Colloidal Multinary Lead Halide Perovskite Nanocrystals Using an Automated Microfluidic Platform. ACS Nano 2018, 12 (6), 5504-5517.

(54) Zou, W.; Li, R.; Zhang, S.; Liu, Y.; Wang, N.; Cao, Y.; Miao, Y.; Xu, M.; Guo, Q.; Di, D.; Zhang, L.; Yi, C.; Gao, F.; Friend, R. H.; Wang, J.; Huang, W. Minimising Efficiency Roll-Off In HighBrightness Perovskite Light-Emitting Diodes. Nat. Commun. 2018, 9 (1), 608.

(55) Zhang, S.; Yi, C.; Wang, N.; Sun, Y.; Zou, W.; Wei, Y.; Cao, Y.; Miao, Y.; Li, R.; Yin, Y.; Zhao, N.; Wang, J.; Huang, W. Efficient Red Perovskite Light-Emitting Diodes Based on Solution-Processed Multiple Quantum Wells. Adv. Mater. 2017, 29 (22), 1606600.

(56) Cao, Y.; Wang, N.; Tian, H.; Guo, J.; Wei, Y.; Chen, H.; Miao, Y.; Zou, W.; Pan, K.; He, Y.; Cao, H.; Ke, Y.; Xu, M.; Wang, Y.; Yang, M.; Du, K.; Fu, Z.; Kong, D.; Dai, D.; Jin, Y.; Li, G.; Li, H.; Peng, Q.; Wang, J.; Huang, W. Perovskite Light-Emitting Diodes Based on Spontaneously Formed Submicrometre-Scale Structures. Nature 2018, 562 (7726), 249-253.

(57) Zhao, B.; Bai, S.; Kim, V.; Lamboll, R.; Shivanna, R.; Auras, F.; Richter, J. M.; Yang, L.; Dai, L.; Alsari, M.; She, X.-J.; Liang, L.; Zhang, J.; Lilliu, S.; Gao, P.; Snaith, H. J.; Wang, J.; Greenham, N. C.; Friend, R. H.; Di, D. High-Efficiency Perovskite-Polymer Bulk Heterostructure Light-Emitting Diodes. Nat. Photonics 2018, 12 (12), $783-789$.

(58) Zhang, C.; Turyanska, L.; Cao, H.; Zhao, L.; Fay, M. W.; Temperton, R.; O'Shea, J.; Thomas, N. R.; Wang, K.; Luan, W.; Patane, A. Hybrid Light Emitting Diodes Based on Stable, High Brightness All-Inorganic $\mathrm{CsPbI}_{3}$ Perovskite Nanocrystals and InGaN. Nanoscale 2019, 11 (28), 13450-13457.

(59) Wang, Q.; Ren, J.; Peng, X.-F.; Ji, X.-X.; Yang, X.-H. Efficient Sky-Blue Perovskite Light-Emitting Devices Based on Ethylammonium Bromide Induced Layered Perovskites. ACS Appl. Mater. Interfaces 2017, 9 (35), 29901-29906.

(60) Hou, S.; Gangishetty, M. K.; Quan, Q.; Congreve, D. N. Efficient Blue and White Perovskite Light-Emitting Diodes via Manganese Doping. Joule 2018, 2 (11), 2421-2433.

(61) Gangishetty, M. K.; Sanders, S. N.; Congreve, D. N. $\mathrm{Mn}^{2+}$ Doping Enhances the Brightness, Efficiency, and Stability of Bulk Perovskite Light-Emitting Diodes. ACS Photonics 2019, 6 (5), 11111117.

(62) Ochsenbein, S. T.; Krieg, F.; Shynkarenko, Y.; Raino, G.; Kovalenko, M. V. Engineering Color-Stable Blue Light-Emitting Diodes with Lead Halide Perovskite Nanocrystals. ACS Appl. Mater. Interfaces 2019, 11 (24), 21655-21660.

(63) Kumar, S.; Jagielski, J.; Yakunin, S.; Rice, P.; Chiu, Y.-C.; Wang, M.; Nedelcu, G.; Kim, Y.; Lin, S.; Santos, E. J. G.; Kovalenko, M. V.; Shih, C.-J. Efficient Blue Electroluminescence Using QuantumConfined Two-Dimensional Perovskites. ACS Nano 2016, 10 (10), 9720-9729.

(64) Xing, J.; Zhao, Y.; Askerka, M.; Quan, L. N.; Gong, X.; Zhao, W.; Zhao, J.; Tan, H.; Long, G.; Gao, L.; Yang, Z.; Voznyy, O.; Tang, J.; Lu, Z.-H.; Xiong, Q.; Sargent, E. H. Color-Stable Highly Luminescent Sky-Blue Perovskite Light-Emitting Diodes. Nat. Commun. 2018, 9 (1), 3541.

(65) Vashishtha, P.; Halpert, J. E. Field-Driven Ion Migration and Color Instability in Red-Emitting Mixed Halide Perovskite Nanocrystal Light-Emitting Diodes. Chem. Mater. 2017, 29 (14), 59655973.

(66) Liu, Y.; Cui, J.; Du, K.; Tian, H.; He, Z.; Zhou, Q.; Yang, Z.; Deng, Y.; Chen, D.; Zuo, X.; Ren, Y.; Wang, L.; Zhu, H.; Zhao, B.; Di, D.; Wang, J.; Friend, R. H.; Jin, Y. Efficient Blue Light-Emitting Diodes Based on Quantum-Confined Bromide Perovskite Nanostructures. Nat. Photonics 2019, DOI: 10.1038/s41566-019-0505-4.

(67) Pan, J.; Quan, L. N.; Zhao, Y.; Peng, W.; Murali, B.; Sarmah, S. P.; Yuan, M.; Sinatra, L.; Alyami, N. M.; Liu, J.; Yassitepe, E.; Yang, 
Z.; Voznyy, O.; Comin, R.; Hedhili, M. N.; Mohammed, O. F.; Lu, Z. H.; Kim, D. H.; Sargent, E. H.; Bakr, O. M. Highly Efficient Perovskite-Quantum-Dot Light-Emitting Diodes by Surface Engineering. Adv. Mater. 2016, 28 (39), 8718-8725.

(68) Hoshi, K.; Chiba, T.; Sato, J.; Hayashi, Y.; Takahashi, Y.; Ebe, H.; Ohisa, S.; Kido, J. Purification of Perovskite Quantum Dots Using Low-Dielectric-Constant Washing Solvent "Diglyme" for Highly Efficient Light-Emitting Devices. ACS Appl. Mater. Interfaces 2018, 10 (29), 24607-24612.

(69) Chiba, T.; Hoshi, K.; Pu, Y.-J.; Takeda, Y.; Hayashi, Y.; Ohisa, S.; Kawata, S.; Kido, J. High-Efficiency Perovskite Quantum-Dot Light-Emitting Devices by Effective Washing Process and Interfacial Energy Level Alignment. ACS Appl. Mater. Interfaces 2017, 9 (21), 18054-18060.

(70) Park, J. H.; Lee, A.-y.; Yu, J. C.; Nam, Y. S.; Choi, Y.; Park, J.; Song, M. H. Surface Ligand Engineering for Efficient Perovskite Nanocrystal-Based Light-Emitting Diodes. ACS Appl. Mater. Interfaces 2019, 11 (8), 8428-8435.

(71) Moyen, E.; Jun, H.; Kim, H.-M.; Jang, J. Surface Engineering of Room Temperature-Grown Inorganic Perovskite Quantum Dots for Highly Efficient Inverted Light-Emitting Diodes. ACS Appl. Mater. Interfaces 2018, 10 (49), 42647-42656.

(72) Shin, Y. S.; Yoon, Y. J.; Lee, K. T.; Jeong, J.; Park, S. Y.; Kim, G. H.; Kim, J. Y. Vivid and Fully Saturated Blue Light-Emitting Diodes Based on Ligand-Modified Halide Perovskite Nanocrystals. ACS Appl. Mater. Interfaces 2019, 11 (26), 23401-23409.

(73) Lu, M.; Zhang, X.; Bai, X.; Wu, H.; Shen, X.; Zhang, Y.; Zhang, W.; Zheng, W.; Song, H.; Yu, W. W.; Rogach, A. L. Spontaneous Silver Doping and Surface Passivation of $\mathrm{CsPbI}_{3}$ Perovskite Active Layer Enable Light-Emitting Devices with an External Quantum Efficiency of 11.2\%. ACS Energy Lett 2018, 3 (7), 1571-1577.

(74) Bodnarchuk, M. I.; Boehme, S. C.; ten Brinck, S.; Bernasconi, C.; Shynkarenko, Y.; Krieg, F.; Widmer, R.; Aeschlimann, B.; Günther, D.; Kovalenko, M. V.; Infante, I. Rationalizing and Controlling the Surface Structure and Electronic Passivation of Cesium Lead Halide Nanocrystals. ACS Energy Lett 2019, 4 (1), 6374.

(75) Nenon, D. P.; Pressler, K.; Kang, J.; Koscher, B. A.; Olshansky, J. H.; Osowiecki, W. T.; Koc, M. A.; Wang, L. W.; Alivisatos, A. P. Design Principles for Trap-Free $\mathrm{CsPbX}_{3}$ Nanocrystals: Enumerating and Eliminating Surface Halide Vacancies with Softer Lewis Bases. J. Am. Chem. Soc. 2018, 140 (50), 17760-17772.

(76) Imran, M.; Ijaz, P.; Goldoni, L.; Maggioni, D.; Petralanda, U.; Prato, M.; Almeida, G.; Infante, I.; Manna, L. Simultaneous Cationic and Anionic Ligand Exchange for Colloidally Stable $\mathrm{CsPbBr}_{3}$ Nanocrystals. ACS Energy Lett 2019, 4 (4), 819-824.

(77) Almeida, G.; Ashton, O. J.; Goldoni, L.; Maggioni, D.; Petralanda, U.; Mishra, N.; Akkerman, Q. A.; Infante, I.; Snaith, H. J.; Manna, L. The Phosphine Oxide Route toward Lead Halide Perovskite Nanocrystals. J. Am. Chem. Soc. 2018, 140 (44), 1487814886.

(78) De Roo, J.; Ibáñez, M.; Geiregat, P.; Nedelcu, G.; Walravens, W.; Maes, J.; Martins, J. C.; Van Driessche, I.; Kovalenko, M. V.; Hens, Z. Highly Dynamic Ligand Binding and Light Absorption Coefficient of Cesium Lead Bromide Perovskite Nanocrystals. ACS Nano 2016, 10 (2), 2071-2081.

(79) Ravi, V. K.; Santra, P. K.; Joshi, N.; Chugh, J.; Singh, S. K.; Rensmo, H.; Ghosh, P.; Nag, A. Origin of the Substitution Mechanism for the Binding of Organic Ligands on the Surface of $\mathrm{CsPbBr}_{3}$ Perovskite Nanocubes. J. Phys. Chem. Lett. 2017, 8 (20), 4988-4994.

(80) Wang, S.; Wang, Y.; Zhang, Y.; Zhang, X.; Shen, X.; Zhuang, X.; Lu, P.; Yu, W. W.; Kershaw, S. V.; Rogach, A. L. Cesium Lead Chloride/Bromide Perovskite Quantum Dots with Strong Blue Emission Realized via a Nitrate-Induced Selective Surface Defect Elimination Process. J. Phys. Chem. Lett. 2019, 10 (1), 90-96.

(81) Nedelcu, G.; Protesescu, L.; Yakunin, S.; Bodnarchuk, M. I.; Grotevent, M. J.; Kovalenko, M. V. Fast Anion-Exchange in Highly
Luminescent Nanocrystals of Cesium Lead Halide Perovskites $(\mathrm{CsPbX}, \mathrm{X}=\mathrm{Cl}, \mathrm{Br}, \mathrm{I})$. Nano Lett. 2015, 15 (8), 5635-5640.

(82) Akkerman, Q. A.; D'Innocenzo, V.; Accornero, S.; Scarpellini, A.; Petrozza, A.; Prato, M.; Manna, L. Tuning the Optical Properties of Cesium Lead Halide Perovskite Nanocrystals by Anion Exchange Reactions. J. Am. Chem. Soc. 2015, 137 (32), 10276-81.

(83) Minh, D. N.; Kim, J.; Hyon, J.; Sim, J. H.; Sowlih, H. H.; Seo, C.; Nam, J.; Eom, S.; Suk, S.; Lee, S.; Kim, E.; Kang, Y. RoomTemperature Synthesis of Widely Tunable Formamidinium Lead Halide Perovskite Nanocrystals. Chem. Mater. 2017, 29 (13), 57135719.

(84) Levchuk, I.; Osvet, A.; Tang, X.; Brandl, M.; Perea, J. D.; Hoegl, F.; Matt, G. J.; Hock, R.; Batentschuk, M.; Brabec, C. J. Brightly Luminescent and Color-Tunable Formamidinium Lead Halide Perovskite $\mathrm{FAPbX}_{3}(\mathrm{X}=\mathrm{Cl}, \mathrm{Br}, \mathrm{I})$ Colloidal Nanocrystals. Nano Lett. 2017, 17 (5), 2765-2770.

(85) Lignos, I.; Protesescu, L.; Emiroglu, D. B.; Maceiczyk, R.; Schneider, S.; Kovalenko, M. V.; deMello, A. J. Unveiling the Shape Evolution and Halide-Ion-Segregation in Blue-Emitting Formamidinium Lead Halide Perovskite Nanocrystals Using an Automated Microfluidic Platform. Nano Lett. 2018, 18 (2), 1246-1252.

(86) Sercel, P. C.; Lyons, J. L.; Wickramaratne, D.; Vaxenburg, R.; Bernstein, N.; Efros, A. L. Exciton Fine Structure in Perovskite Nanocrystals. Nano Lett. 2019, 19 (6), 4068-4077.

(87) Song, J.; Li, J.; Xu, L.; Li, J.; Zhang, F.; Han, B.; Shan, Q.; Zeng, H. Room-Temperature Triple-Ligand Surface Engineering Synergistically Boosts Ink Stability, Recombination Dynamics, and Charge Injection toward EQE-11.6\% Perovskite QLEDs. Adv. Mater. 2018, 30 (30), 1800764.

(88) Zhang, H.; Fu, X.; Tang, Y.; Wang, H.; Zhang, C.; Yu, W. W.; Wang, X.; Zhang, Y.; Xiao, M. Phase Segregation Due To Ion Migration In All-Inorganic Mixed-Halide Perovskite Nanocrystals. Nat. Commun. 2019, 10 (1), 1088.

(89) Lee, H.; Ko, D.; Lee, C. Direct Evidence of Ion-MigrationInduced Degradation of Ultrabright Perovskite Light-Emitting Diodes. ACS Appl. Mater. Interfaces 2019, 11 (12), 11667-11673.

(90) Gualdron-Reyes, A. F.; Yoon, S. J.; Barea, E. M.; Agouram, S.; Munoz-Sanjose, V.; Melendez, A. M.; Nino-Gomez, M. E.; MoraSero, I. Controlling the Phase Segregation in Mixed Halide Perovskites through Nanocrystal Size. ACS Energy Lett 2019, 4 (1), 54-62.

(91) Peng, W.; Aranda, C.; Bakr, O. M.; Garcia-Belmonte, G.; Bisquert, J.; Guerrero, A. Quantification of Ionic Diffusion in Lead Halide Perovskite Single Crystals. ACS Energy Lett 2018, 3 (7), $1477-1481$

(92) Knight, A. J.; Wright, A. D.; Patel, J. B.; McMeekin, D. P.; Snaith, H. J.; Johnston, M. B.; Herz, L. M. Electronic Traps and Phase Segregation in Lead Mixed-Halide Perovskite. ACS Energy Lett 2019, 4 (1), $75-84$.

(93) Zhang, H.; Fu, X.; Tang, Y.; Wang, H.; Zhang, C.; Yu, W. W.; Wang, X.; Zhang, Y.; Xiao, M. Phase Segregation due to Ion Migration in All-Inorganic Mixed-Halide Perovskite Nanocrystals. Nat. Commun. 2019, 10 (1), 1088. 